\title{
Cytomegalovirus infection in a patient with Crohn's ileocolitis
}

\author{
Sahin Coban MD ${ }^{1}$, Arzu Ensari MD², Mehmet Ayhan Kuzu MD FACS ${ }^{3}$, Samet Yalcin MD $^{3}$, \\ Murat Palabiyikoglu MD¹, Necati Ormeci MD ${ }^{1}$
}

S Coban, A Ensari, MA Kuzu, S Yalcin, M Palabiyikoglu, N Ormeci. Cytomegalovirus infection in a patient with Crohn's ileocolitis. Can J Gastroenterol 2005;19(2):109-111.

Cytomegaloviral enterocolitis is an uncommon infection that can complicate inflammatory bowel disease. A case of a patient with a three-year history of Crohn's disease is reported. He had been in a stable condition on mesalamine $4 \mathrm{~g} /$ day and methylprednisolone $10 \mathrm{mg} /$ day for three years until four weeks before admission. The patient was admitted with complaints of fever, abdominal pain and watery diarrhea. A diagnosis of an exacerbation of Crohn's disease was established. The radiological examination revealed narrowing of the terminal ileum. Multiple fistulas and abscess-like images were observed. The patient then underwent ileocolic resection and ileostomy. The histopathological examination revealed Crohn's ileocolitis with superimposed cytomegalovirus infection. In patients with rapidly deteriorating inflammatory bowel disease, cytomegalovirus infection should be kept in mind as one of the differential diagnoses.

\section{Infection à CMV chez un patient souffrant de la maladie de Crohn}

\begin{abstract}
L'entérocolite à cytomégalovirus (CMV) est une infection rare qui peut compliquer la maladie inflammatoire de l'intestin. On fait ici état du cas d'un patient chez qui la maladie de Crohn a été diagnostiquée il y a trois ans. Son état était stationnaire depuis lors, avec $4 \mathrm{~g}$ de mésalamine et $10 \mathrm{mg}$ de méthylprednisolone par jour, jusqu'à quatre semaines avant son admission. Le patient s'est présenté avec des symptômes de fièvre, douleur abdominale et diarrhée liquide. Un diagnostic d'exacerbation de la maladie de Crohn a été posé. L'examen radiologique a révélé un rétrécissement de l'iléon terminal et la présence de nombreuses fistules et pseudo-abscès. Le patient a subi une résection iléocolique et une iléostomie. L'examen histopathologique a révélé une iléocolite de Crohn compliquée d'une infection à CMV. Chez les patients dont la maladie inflammatoire de l'intestin s'aggrave subitement, il faut envisager la possibilité d'une infection à CMV parmi les diagnostics différentiels.
\end{abstract}

Key Words: Crohn's ileocolitis; Cytomegalovirus; Inflammatory bowel disease

Cytomegalovirus (CMV) is a herpes virus that infects $40 \%$ to $100 \%$ of adults in different populations by their fourth decade of life (1). However, CMV infection is usually asymptomatic in humans (2).

CMV infection has been described as an opportunistic infection found in patients following renal or bone marrow transplantation, AIDS, hematological malignancies or during treatment with chemotherapy or corticosteroids $(2,3)$. It has a severe clinical course and may be fatal unless treated early on (4). The disease may present with a more severe clinical course in the elderly and neonates, and patients with comorbidities such as cancer (5).

CMV infection is well-defined in patients with inflammatory bowel disease (IBD) as an opportunistic infection leading to relapse, especially in patients with steroid-resistant disease $(6,7)$. Patients with IBD are at a higher risk of CMV infection because they commonly use immunosuppressive therapies, and they have an altered immune status as a result of malnutrition (8). The infection most commonly affects the colon; however, it may disseminate throughout the gastrointestinal tract.

A case of postoperatively detected CMV infection in a patient with Crohn's ileocolitis is presented.

\section{CASE PRESENTATION}

A 50-year-old man was admitted to the gastroenterology clinic at the Ankara University Medical School in Turkey with complaints of fever, abdominal pain and watery diarrhea. The history revealed Crohn's disease that had been first diagnosed three years before. He had been in a stable condition on mesalamine ( $4 \mathrm{~g} /$ day) and low-dose steroids $(10 \mathrm{mg} /$ day $)$ for three years until four weeks before admission. On admission, the patient appeared to be chronically ill. His vital findings were as follows: blood pressure 120/70 $\mathrm{mmHg}$; pulse 90 beats/min; temperature $38^{\circ} \mathrm{C}$; and respiration rate 18 breaths $/ \mathrm{min}$. The physical examination revealed tenderness of the right lower quadrant and conjunctival pallor. The laboratory findings were sedimentation rate $90 \mathrm{~mm} / \mathrm{h}$; C-reactive protein $291 \mathrm{mg} / \mathrm{L}$; white blood cell $16,200 / \mathrm{mm}^{3}$; hemoglobin $112 \mathrm{~g} / \mathrm{L}$; platelets $457,000 / \mathrm{mm}^{3}$; prothrombin time $13.3 \mathrm{~s}$; international normalized ratio 1.1; partial thromboplastin time $28.3 \mathrm{~s}$; glucose $6.9 \mathrm{mmol} / \mathrm{L}$; blood urea nitrogen $6.42 \mathrm{mg} / \mathrm{dL}$; creatinine $106 \mathrm{mg} / \mathrm{dL}$; calcium $9 \mathrm{meq} / \mathrm{L}$; sodium $135 \mathrm{meq} / \mathrm{L}$; potassium $3.8 \mathrm{meq} / \mathrm{L}$; aspartate aminotransferase $0.45 \mathrm{U} / \mathrm{L}$; alanine aminotransferase $0.40 \mathrm{U} / \mathrm{L}$; total protein $40.1 \mathrm{~g} / \mathrm{dL}$; albumin $19 \mathrm{~g} / \mathrm{dL}$; total bilirubin $30.8 \mathrm{mg} / \mathrm{dL}$; and direct bilirubin $12 \mathrm{mg} / \mathrm{dL}$. Immune markers including

\footnotetext{
${ }^{1}$ Department of Gastroenterology, ${ }^{2}$ Department of Pathology, ${ }^{3}$ Department of General Surgery, Ankara University Medical School, Ankara, Turkey

Correspondence: Dr Sahin Coban, 39 Cd. Pembe Kosk Apt 1/4, Cukurambar, Balgat, 06540, Ankara, Turkey. Telephone 90-312-286-6803, fax 90-312-310-6371, e-mail scoban72@yahoo.com

Received for publication May 27, 2004. Accepted September 28, 2004
} 


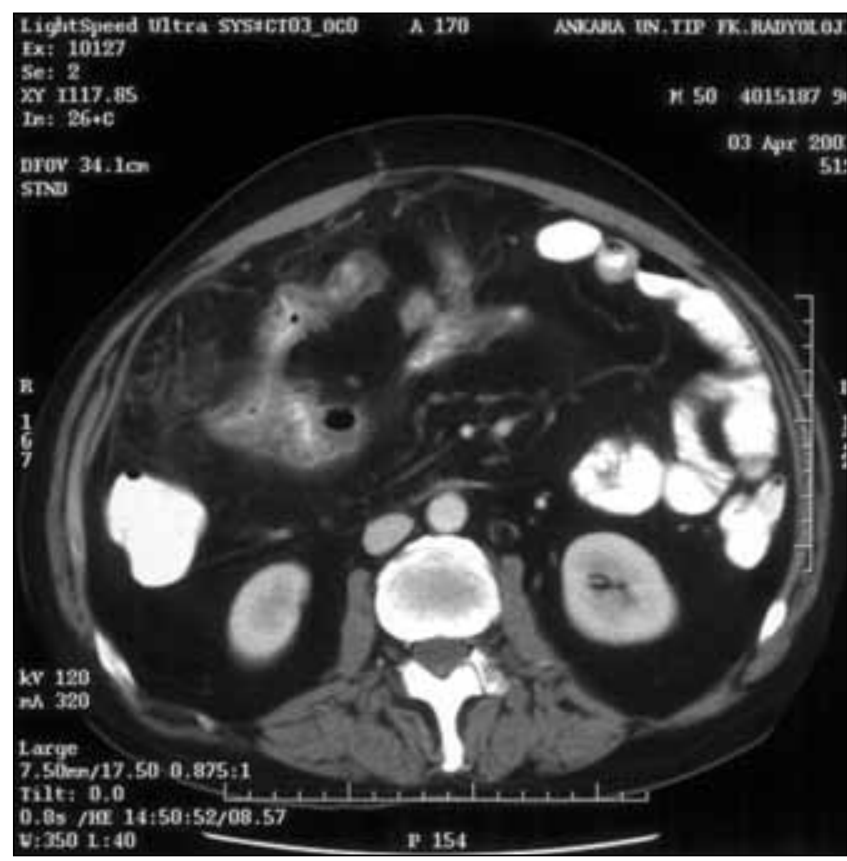

Figure 1) Intravenous contrast-enhanced computed tomography showing inflammation and abscesses in the mesentery in the umblical region and adjacent small intestine, and in the subhepatic region

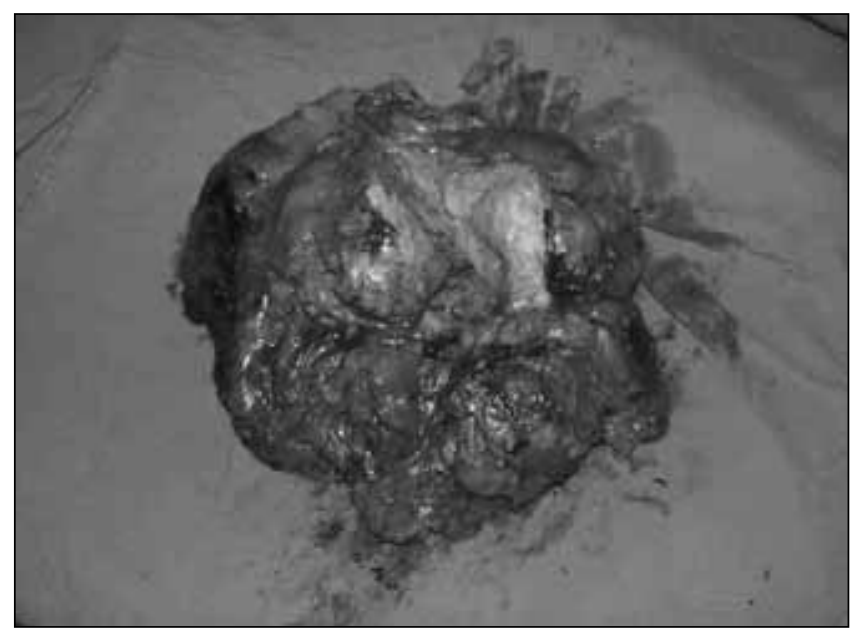

Figure 2) Resected inflammatory mass

antinuclear antibodies, antimitochondrial antibodies, antismooth muscle antibodies and antineutrophil cytoplasmic antibodies were all negative. The patient was diagnosed with an exacerbation of Crohn's disease, and an elemental diet, mesalamine therapy at a daily dose of $4 \mathrm{~g}$ and prednisolone therapy at a daily dose of $60 \mathrm{mg}$ were started.

The radiological examination of the small intestine demonstrated narrowing of the terminal ileum and thickening on the wall of the small bowel. Multiple fistula and abscess-like images were also observed. On abdominal ultrasonography, there was thickening on the wall of terminal ileum. Abdominal computed tomography revealed an abscess of $1.5 \mathrm{~cm}$ in diameter in the mesentery in the umbilical region and adjacent small intestine, and a second small abscess was

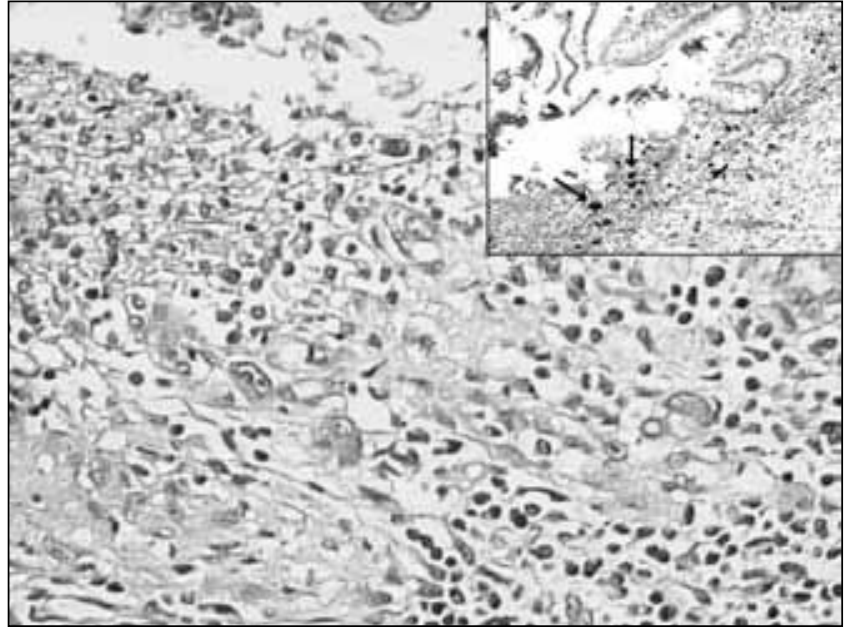

Figure 3) Intranuclear inclusion bodies suggestive of cytomegalovirus $(\mathrm{CMV})$ infection within endothelial cells at the base of an ulcer (hematoxylin and eosin stain, original magnification $\times 400$ ). Inset shows large cells staining positively with anti-CMV antibody in the same field (streptavidin-peroxidase stain; original magnification $\times 200$ )

observed in the subhepatic region (Figure 1). Exploration revealed an inflammatory mass affecting $50 \mathrm{~cm}$ of the terminal ileum and the right colon up to the transverse colon. Interloop abscess and enteroenteric fistula formation was detected. Because of the dense adhesion and inflammation, 'en bloc' resection of this inflammatory mass was performed (Figure 2). End ileostomy was performed and the distal transverse colon was oversewn. After the operation, the patient gradually improved. Gross examination of the surgical specimen revealed linear ulcers throughout the small intestine and the colon. There were segmental strictures, peri-ileal abscesses and enteroenteric fistula formation in the ileal loops where the bowel wall was thickened.

Microscopically, there were fissuring ulcers and lymphoid aggregates within the bowel walls of both bowel segments. Inflammatory infiltrate extended throughout the thickness of the wall. No granulomas were observed. There were numerous large nuclei at the base of the ulcers and within the surrounding mucosal areas where there was extensive pyloric metaplasia. These cytopathic changes were largely confined to the endothelial cells, which stained positively with CD31. The immunohistochemical examination clearly indicated that these nuclei were strongly positive with anti-CMV antibody (Figure 3). A diagnosis of Crohn's ileocolitis with superimposed CMV infection was established in light of these findings.

Six months following the first operation, the patient underwent another surgery for bowel continuity. Postoperative follow-up was uneventful at one year.

\section{DISCUSSION}

CMV is a common virus which infects approximately twothirds of the general population. CMV has been reported to act on the intestine as a nonpathogenic bystander (4). The majority of infections are not clinically obvious, but CMV may cause clinically significant disease throughout the gastrointestinal tract (9). CMV enterocolitis in adult patients is usually caused by reactivation of the latent virus in an immunocompromised state, such as AIDS patients, transplant 
recipients or corticosteroid treatment (2). In addition, CMV infection may play a role in the natural history of IBD (10), increasing the risk of exacerbations (4), severe complications and refractory pouchitis in the patients with proctocolectomies and ileoanal reservoirs (11). However, there are some reports suggesting that CMV infection affects the clinical course of IBD. Cases of patients with self-limited colitis and colonic ulcers associated with CMV have been reported (6,12). An association between CMV infection and the onset of IBD has also been presented $(13,14)$. In the present case, CMV serological markers of the patient were not studied preoperatively. However, the patient's clinical condition deteriorated while he was in remission with low-dose steroid therapy, which suggested that Crohn's disease may have preceded CMV infection or developed concomitantly.

A study by Cottone et al (15) in which 62 cases of patients with severe colitis were studied, seven of 19 (37\%) steroidresistant patients had CMV infection. Two of these patients also had a history of Crohn's disease. After surgery, CMV infection was detected in the surgical specimen of one patient. In this study, the patients with CMV colitis had a history of steroid use longer than three months (15). Similarly, the surgical specimen of our case revealed CMV infection, and the patient had a history of low-dose steroid use for longer than three months.

CMV infection of the ileum has rarely been reported. One of these reports (16) involved a patient with CMV infection

\section{REFERENCES}

1. Carlstroem G. Virologic studies on cytomegalic inclusion disease. Acta Paediatr Scand 1965;54:17-23.

2. Goodgame RW. Gastrointestinal cytomegalovirus disease. Ann Intern Med 1993;119:924-35.

3. Surawicz CM, Myerson D. Self-limited cytomegalovirus colitis in immunocompetent individuals. Gastroenterology 1988;94:194-9.

4. Vega R, Bertran X, Menacho M, et al. Cytomegalovirus infection in patients with inflammatory bowel disease. Am J Gastroenterol 1999;94:1053-6.

5. Kanno M, Chandrasekar PH, Bentley G, Vander Heide RS, Alangaden GJ. Disseminated cytomegalovirus disease in hosts without acquired immunodeficiency syndrome and without an organ transplant. Clin Infect Dis 2001;32:313-6.

6. Loftus EV Jr, Alexander GL, Carpenter HA. Cytomegalovirus as an exacerbating factor in ulcerative colitis. J Clin Gastroenterol 1994;19:306-9.

7. Rachima C, Maoz E, Apter S, Thaler M, Grossman E, Rosenthal T. Cytomegalovirus infection associated with ulcerative colitis in immunocompetent individuals. Postgrad Med J 1998;74:486-9.

8. Papadakis KA, Tung JK, Binder SW, et al. Outcome of cytomegalovirus infections in patients with inflammatory bowel disease. Am J Gastroenterol 2001;96:2137-42.

9. Pfau P, Kochman ML, Furth EE, Lichtenstein GR. Cytomegalovirus colitis complicating ulcerative colitis in the steroid-naive patient. Am J Gastroenterol 2001;96:895-9. of the ileum and a squamous cell carcinoma of the tongue, although the patient was not immunocompromised. In another study (17), CMV infection was detected in a patient with Crohn's disease presenting with severe ileal bleeding. Vega et al (4) studied nine steroid-resistant IBD patients and found CMV infection in one of the two Crohn's disease patients with both colon and ileum involvement after the operation. The histopathological examination of our patient's specimen revealed CMV inclusion bodies in both the ileum and colon.

\section{CONCLUSION}

IBD patients with severe colitis not responding to treatment should be studied for CMV infection, particularly when the clinical course has deteriorated because of immunosuppression. In Crohn's disease, CMV infection is relatively rare compared with ulcerative colitis. In our patient, the underlying cause for the clinical deterioration and requirement for immediate surgical intervention seems to be CMV infection. CMV infection was detected postoperatively in the patient. If the infection had been detected preoperatively, the patient could have been treated without a need for surgical intervention. Therefore, it can be concluded that early detection and treatment of CMV infection may alter the course of the disease.

10. Berk T, Gordon SJ, Choi HY, Cooper HS. Cytomegalovirus infection of the colon: A possible role in exacerbations of inflammatory bowel disease. Am J Gastroenterol 1985;80:355-60.

11. Moonka D, Furth EE, MacDermott RP, Lichtenstein GR. Pouchitis associated with primary cytomegalovirus infection. Am J Gastroenterol 1998;93:264-6.

12. Cheung AN, Ng IO. Cytomegalovirus infection of the gastrointestinal tract in non-AIDS patients. Am J Gastroenterol 1993;88:1882-6.

13. Orvar K, Murray J, Carmen G, Conklin J. Cytomegalovirus infection associated with onset of inflammatory bowel disease. Dig Dis Sci 1993;38:2307-10.

14. Lortholary O, Perronne C, Leport J, Leport C, Vilde JL. Primary cytomegalovirus infection with the onset of ulcerative colitis. Eur J Clin Microbiol Infect Dis 1993;12:570-2.

15. Cottone M, Pietrosi G, Martorana G, et al. Prevalence of cytomegalovirus infection in severe refractory ulcerative and Crohn's colitis. Am J Gastroenterol 2001;96:773-5.

16. Weber FH Jr, Frierson HF Jr, Myers BM. Cytomegalovirus as a cause of isolated severe ileal bleeding. J Clin Gastroenterol 1992;14:52-5.

17. Sekine Y, Yamamoto H, Miyata T, et al. Systemic cytomegalovirus infection with severe ileal bleeding associated with Crohn's disease. Am J Gastroenterol 2001;96:1653-4. 


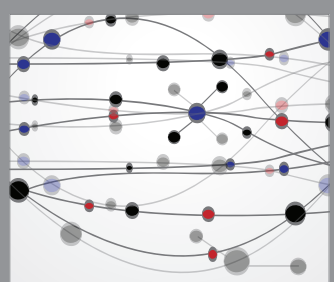

The Scientific World Journal
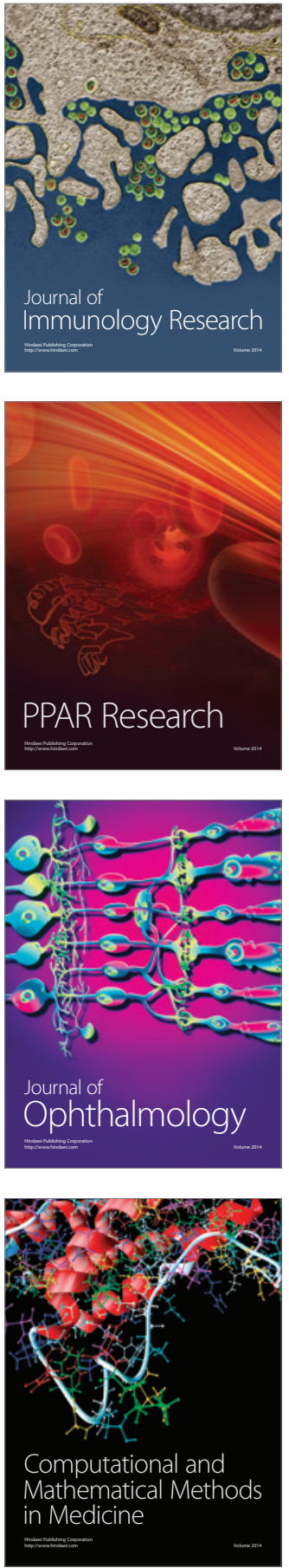

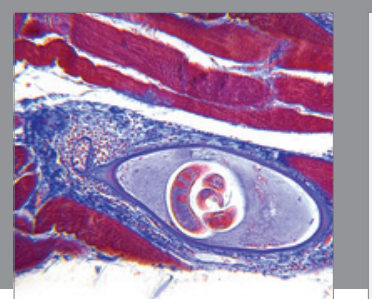

Gastroenterology Research and Practice

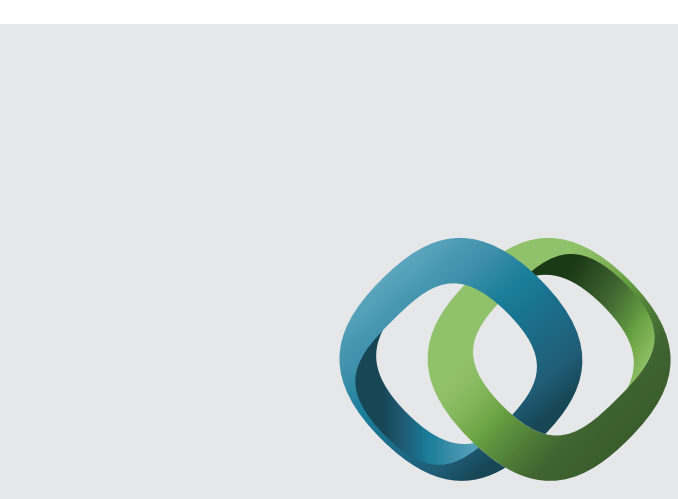

\section{Hindawi}

Submit your manuscripts at

http://www.hindawi.com
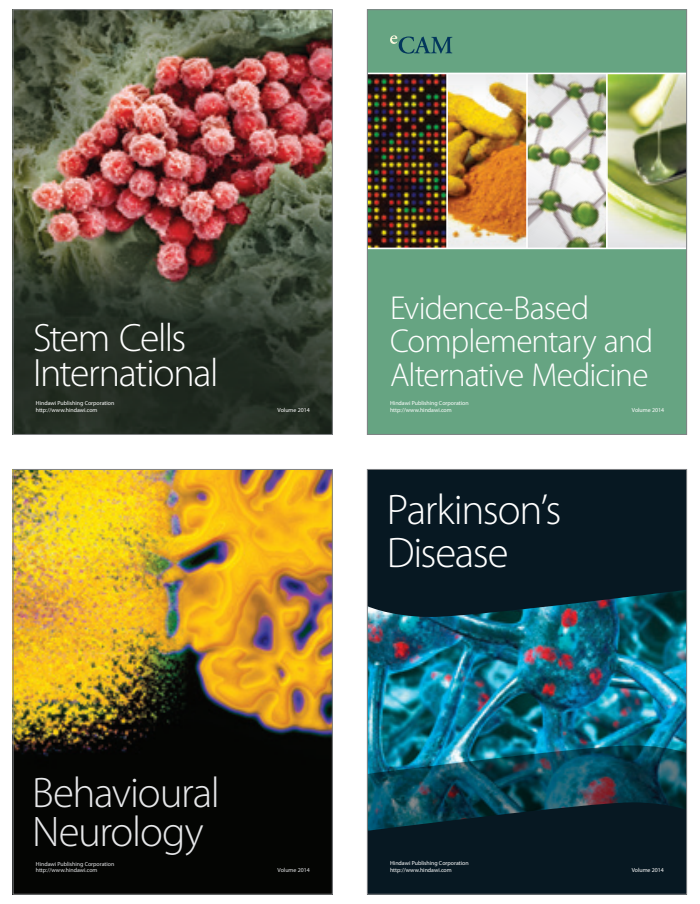
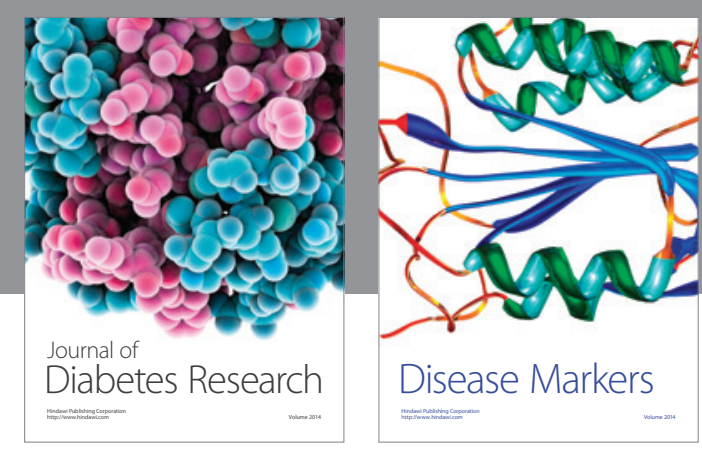

Disease Markers
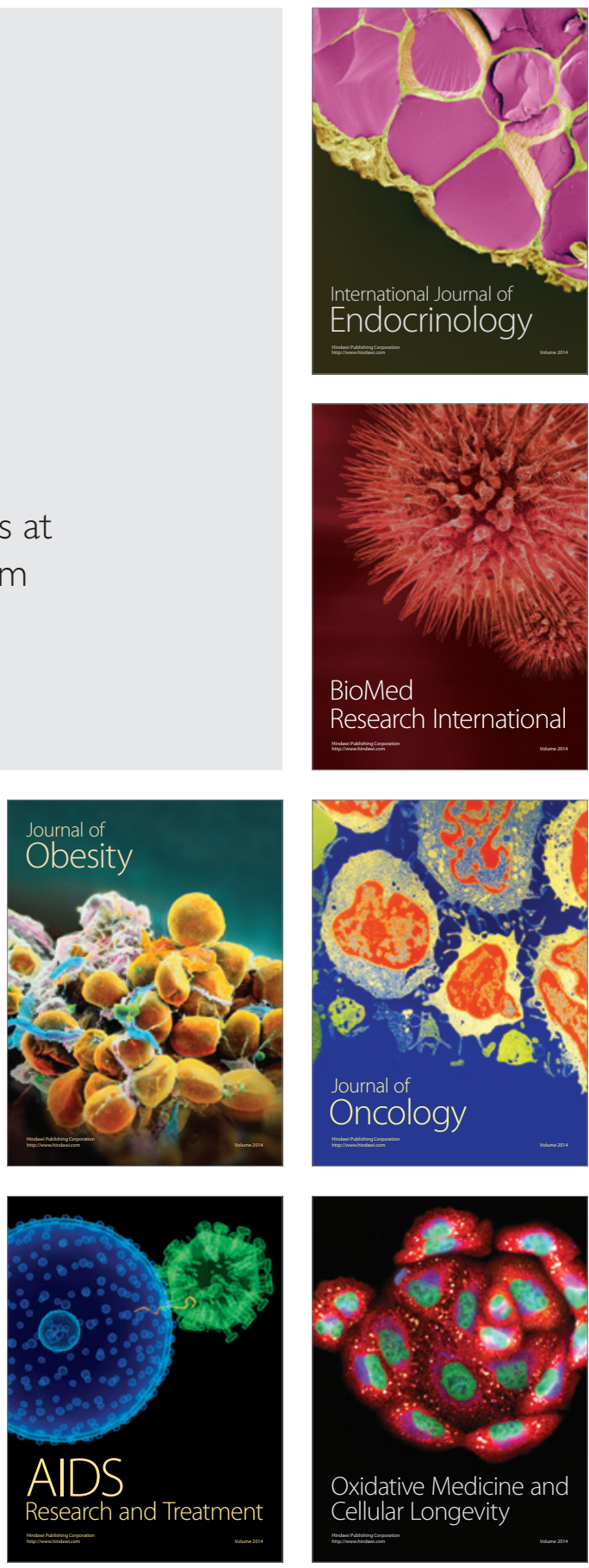